\title{
Photobiomodulation Improves the Inflammatory Response and Intracellular Signaling Proteins Linked To Vascular Function and Cell Survival in the Brain of Aged Rats
}

Fabrizio Cardoso ( $\square$ fabrizioscardoso@yahoo.com.br)

Universidade de Mogi das Cruzes Nucleo de Ciencias Saude https://orcid.org/0000-0002-7547-8880

Fernanda Mansur

Hospital israelita Albert Einstein

Bruno Araújo

Centro Nacional de Pesquisa em Energia e Materiais

Francisco Gonzalez-Lima

University of Texas at Austin

Sérgio Gomes da Silva

Universidade de Mogi das Cruzes

\section{Research Article}

Keywords: laser, photobiomodulation, brain, aging, inflammation, intracellular signaling proteins

Posted Date: March 10th, 2021

DOI: https://doi.org/10.21203/rs.3.rs-293139/v1

License: (c) (i) This work is licensed under a Creative Commons Attribution 4.0 International License.

Read Full License 


\section{Abstract}

Photobiomodulation is a non-pharmacological tool widely used to reduce inflammation in many tissues. However, little is known about its effects on the inflammatory response in the aged brain. We conducted the study to examine anti-inflammatory effects of photobiomodulation in aging brains. We used aged rats (20 months old) with control (handled, laser off) or transcranial laser (660 nm wavelength, $100 \mathrm{~mW}$ power) treatments for 10 consecutive days and evaluated the level of inflammatory cytokines and chemokines, and the expression and activation of intracellular signaling proteins in the cerebral cortex and the hippocampus. Inflammatory analysis showed that aged rats submitted to transcranial laser treatment had increased levels of IL-1alpha and decreased levels of IL-5 in the cerebral cortex. In the hippocampus, the laser treatment increased the levels of IL-1alpha and decreased levels of IL-5, IL-18 and fractalkine. Regarding the intracellular signaling proteins, a reduction in the ERK and p38 expression and an increase in the STAT3 and ERK activation were observed in the cerebral cortex of aged rats from the laser group. In addition, the laser treatment increased the hippocampal expression of p70S6K, STAT3 and p38 of aged rats. Taken together, our data indicate that transcranial photobiomodulation can improve the inflammatory response and the activation of intracellular signaling proteins linked to vascular function and cell survival in the aged brain.

\section{Highlights}

(1) Photobiomodulation improves the inflammatory response in the cortex and hippocampus of aged rats

(2) Photobiomodulation activates intracellular signaling proteins linked to vascular function and cell survival in the brain of aged rats

\section{Introduction}

Photobiomodulation (PBM), also called low-level laser therapy (Anders et al., 2015) has emerged as a non-pharmacological, non-invasive tool capable of stimulating wound healing, reducing pain and inflammation in several diseases (Chung et al., 2012). Many human studies have also used transcranial PBM to improve brain functions in several conditions (e.g., Schiffer et al., 2009; Muili et al., 2012; Muili et al., 2013; Barrett and Gonzalez-Lima, 2013; Tian et al., 2016; Disner et al., 2016; Hwang et al., 2016; Eells et al., 2016; Blanco et al., 2017a; Blanco et al., 2017b; Wang et al., 2017; Saltmarche et al., 2017; Holmes et al., 2019). For example, Saltmarche and collaborators (2017) submitted elderly people diagnosed with dementia to PBM and observed an improvement in executive function and a significant improvement in sleep and mood. Many studies using animal models have also shown interesting results of PBM on the brain (e.g., Rojas et al., 2008; Rojas and Gonzalez-Lima, 2011; El Massri et al., 2017; Lu et al., 2017). For instance, Lu and collaborators (2017) injected beta amyloid (AB) in the hippocampus of rats that were treated with laser PBM for five days. They noted that laser treatment restored spatial memory and object recognition memory. In addition, they observed an increase in the antioxidant capacity of hippocampal CA1 neurons and a decrease of $A \beta$-induced reactive gliosis and inflammation. 
Recently, some authors have shown promising results of PBM in the aged brain (Salgado et al., 2015; Salehpour et al., 2017; Vargas et al., 2017; Salehpour et al., 2018; O'Donnell et al., 2021; Saucedo et al., 2021). However, there is little evidence to explain such effects, other than improved mitochondrial respiration and vascular function. It is known that brain aging is characterized by local inflammation with glial cells releasing increasing amount of pro-inflammatory cytokines such as IL-1beta, IL-6 and TNFalpha (Cribbs et al., 2012; Norden and Godbout, 2013). This process is directly involved with cellular dysfunctions characteristic of aging and Alzheimer's disease (Stephan et al., 2013; Hong et al., 2016), which may result in an increase in the activation of signaling pathways linked to inflammation and cellular death such as c-Jun N-terminal kinase (JNK) and p38 mitogen-activated protein kinase (p38) (O'Donnell et al., 2000).

Based on the well-documented anti-inflammatory effects of PBM in other tissues (Almeida et al., 2013; Haslerud et al., 2017; Tomazoni et al., 2017: Naterstad et al., 2018), we evaluated whether a transcranial treatment with a laser diode of $660 \mathrm{~nm}$ wavelength and $100 \mathrm{~mW}$ power can modulate the inflammatory response and expression and activation of intracellular signaling proteins in the cortex and hippocampus of aged rats.

\section{Methods}

\subsection{Animals}

Twenty-month-old male Wistar rats $(n=10)$ were used in this study. The colony room was maintained at $21 \pm 2^{\circ} \mathrm{C}$ with a $12 \mathrm{~h}$ light/ dark schedule (light: 7 am until $7 \mathrm{pm}$ ), and food and water were provided ad libitum throughout the experimental period. All experimental protocols were approved by the ethics committee of the Universidade de Mogi das Cruzes (UMC) (\#003/2020) and all efforts were made to minimize animal suffering in accordance with the proposals of the International Ethical Guideline for Biomedical Research (CIOMS 1985).

\subsection{Laser and control protocols}

The aged rats were randomly distributed into two groups: laser $(n=5)$ and control $(n=5)$. The animals of the laser group were manually immobilized and received the treatment with a laser diode of $660 \mathrm{~nm}$ wavelength and $100 \mathrm{~mW}$ power for $30 \mathrm{~s}$ at each of 5 irradiation points on the head, totalizing 15 Joules of Energy, $150 \mathrm{~s}$ of irradiation and fluence of $535.7 \mathrm{~J} / \mathrm{cm}^{2}$, for 10 consecutive days. These laser parameters were chosen based on our previous publications, showing that these parameters had antiinflammatory effects in other tissues (Table 1) (Almeida et al., 2013; Haslerud et al., 2017; Tomazoni et al., 2017; Naterstad et al., 2018). The target coordinates on the scalp were: point $1=A P+4.20 \mathrm{~mm}$ and $\mathrm{ML} 0.00 \mathrm{~mm}$; point $2=\mathrm{AP}-3.00 \mathrm{~mm}$ and $\mathrm{ML}-6.60 \mathrm{~mm}$; point $3=\mathrm{AP}-3.00 \mathrm{~mm}$ and $\mathrm{ML}+6.60 \mathrm{~mm}$; point 4 $=$ AP $0.00 \mathrm{~mm}$ and $\mathrm{ML} 0.00 \mathrm{~mm}$; point $5=\mathrm{AP}-5.52 \mathrm{~mm}$ and $\mathrm{ML} 0.00 \mathrm{~mm}$ ), as in our previous metabolomics study in the rat (Cardoso et al., 2021). The animals of the control group were handled the same way, except that the laser was not turned on. 
Table 1

Laser parameters used in the present study.

\begin{tabular}{|ll|}
\hline Parameter (unit) & Measurement method or value information source \\
\hline Center wavelength $(\mathrm{nm})$ & 660 \\
\hline Operating mode & Continuous wave \\
\hline Average radiant power $(\mathrm{W})$ & 0.1 \\
\hline Aperture diameter $(\mathrm{cm})$ & 0.6 \\
\hline Irradiance at aperture $\left(\mathrm{mW} / \mathrm{cm}^{2}\right)$ & 3.33 \\
\hline Beam divergence $($ degree $)$ & Near zero \\
\hline Beam shape & Circular \\
\hline Beam spot size $\left(\mathrm{cm}{ }^{2}\right)$ & 0.03 \\
\hline Exposure duration/point $(\mathrm{s})$ & 30 \\
\hline Radiant exposure $\left(\mathrm{J} / \mathrm{cm}^{2}\right)$ per session & 500.0 \\
\hline Number of points irradiated & 5 \\
\hline Delivery mode & Contact mode \\
\hline Number and frequency of sessions & One session/day for 10 consecutive days \\
\hline Total radiant energy $(\mathrm{J})$ per head & 15 \\
\hline
\end{tabular}

\subsection{Tissue preparation}

One hour after the final laser or control session, aged rats from the laser $(n=5)$ and control $(n=5)$ groups were euthanized by decapitation and their cerebral cortex and hippocampus were immediately collected and frozen. The whole cerebral cortex and the hippocampus were homogenized in ice-cold RIPA lysis buffer (50 mM Tris-HCl, pH 7.5, $150 \mathrm{mM} \mathrm{NaCl}, 0.5 \%$ sodium deoxycholate, 1\% NP-40, 0.1\% SDS) with freshly added protease (Cat\# M222-1 ml; Lot\# 1295C056; Amresco) and phosphatase (Cat\# B15001-A and B; Lot\# 510011; Biotool) inhibitors. Homogenates were centrifuged at 10,000 x g for 10 minutes at $4^{\circ} \mathrm{C}$ and supernatants were collected for cytokine/chemokine quantification.

\subsection{Methods for the protein detection and analysis}

Milliplex® MAP rat cytokine/chemokine magnetic bead panel assay (RECYMAG65K) was used to quantify the levels G-CSF, eotaxin, GM-CSF, IL-1alpha, leptin, MIP-1alpha, IL-4, IL-1beta, IL-2, IL-6, IL-13, IL10, IL-5, IL-17alpha, IL-18, MCP-1, IP-10, VEGF, fractalkine, MIP-2, TNF-alpha, and RANTES in the brain samples of the studied groups. Milliplex® MAP Kits 48-681MAG and 48-680MAG were used to evaluate the expression and brain activation of signaling proteins Akt, p70S6K, STAT3, STAT5, ERK, JNK, NF-kB and $\mathrm{p} 38$. The plates were run on a Luminex ${ }^{\mathrm{Tm}}$ Magpix $^{\mathrm{TW}}$ instrument and results were analyzed with the 
Milliplex Analyst 5.1 Software using a Logistic 5P Weighted regression formula to calculate sample concentrations from the standard curves.

\subsection{Statistical analyses}

Statistical procedures were conducted using the Mann-Whitney U Test that allows comparison of nonparametric data. All analyses were performed using the Statistical Package for the Social Science (SPSS Inc, IBM, version 221.0, Chicago, IL, USA). A statistical difference was considered significant when the $P$ value was lower than 0.05. All plots were acquired using the Graph Pad Prism (6.0).

\section{Results}

\subsection{Cortical and hippocampal levels of cytokines and chemokines}

To evaluate whether the PBM had anti-inflammatory effects on the aged brain, we quantified the cortical and hippocampal levels of several chemokines and cytokines in aged rats submitted to 10 consecutive days of laser treatment or control treatment. The detailed results of Mann-Whitney tests are presented in Supplementary Tables 1 and 2 . The laser treatment increased the cortical level of IL-1alpha $(p=0.008)$ and reduced the IL-5 level $(p=0.046)$ (Fig. 1).

In the hippocampus, an increase in the IL-1alpha $(p=0.035)$ level was observed in the laser group. However, the laser treatment was able to reduce the levels of IL5 ( $p=0.027), I L-18(p=0.049)$ and fractalkine $(p=0.037)$ in aged rats (Fig. 2$)$. Taken together, these data showed that PBM changed the levels of neuroinflammatory markers in aged rats.

\subsection{Cortical and hippocampal expression and activation of signaling proteins}

We investigated the cortical and hippocampal expression and activation of signaling proteins in aged rats submitted to laser treatment vs. control treatment. The detailed results of Mann-Whitney tests are presented in Supplementary Tables 3 and 4 . The laser treatment decreased the cortical expression of ERK $(p=0.028)$ and p38 $(p=0.009)$. Interestingly, the laser treatment was able to increase the cortical activation of ERK $(p=0.014)$ and STAT3 $(p=0.0016)$ (Fig. 3$)$.

In the hippocampus, the laser treatment increased the expression of p70S6K $(p=0.016)$ and STAT5 $(p=$ $0.050)$, and decreased the expression of p38 $(p=0.028)$ in aged rats (Fig. 4).

\section{Discussion}

The aim of our study was to investigate levels of pro- and anti-inflammatory cytokines and chemokines and the expression and activation of signaling proteins in the brain of aged rats submitted to repeated treatment with a laser diode of $660 \mathrm{~nm}$ wavelength and $100 \mathrm{~mW}$ power. Our results indicate that 
transcranial PBM was able to modulate the expression and activation of signaling proteins and the inflammatory profile in the brain of aged rats.

\subsection{Anti-inflammatory effects of PBM on the aged brain}

The laser treatment increased the levels of IL- 1 alpha and decreased the levels of IL- 5 in both the cortex and hippocampus of aged rats. Interestingly, IL-1 alpha has been shown to promote angiogenesis and to increase proliferation and migration of endothelial cells (Saini and Bix, 2012; Salmeron et al., 2016). The IL-1alpha findings are consistent with improving vascular function and oxygenation of the aged brain (Saucedo et al., 2021), which may help explain the facilitation of neurocognitive functions shown by transcranial PBM studies in older humans (Saltmarche et al., 2017; Vargas et al., 2017). In contrast, a reduction of IL-5 may be beneficial to the aged brain because IL- 5 induces proliferation and activation of microglia, which is characteristic of inflammatory reactions (Liva and de Vellis, 2001).

Moreover, PBM promoted an anti-inflammatory effect by reducing the hippocampal levels of IL-18 and fractalkine. IL-18 is a pro-inflammatory cytokine that inhibits cell differentiation and reduces

neurogenesis and induces neuronal death in cultured neural progenitors (Liu et al., 2005; Zhu et al., 2009). Further evidence suggests that IL-18 can activate the p38 signaling pathway (Arend et al., 2008). Also, high levels of this cytokine are observed during aging and in neurodegenerative diseases (Bossù et al., 2010; Bellaver et al., 2017). Fractalkine, in turn, is a chemokine regulated by pro-inflammatory cytokines such as TNFalpha and IL-1 beta, which is involved in the communication between neurons and microglia (Desforges et al., 2012). High levels of fractalkine were observed in the cortex and hippocampus of a rat model of Alzheimer's disease (Hanzel et al., 2014). In this sense, reducing the levels of both IL-18 and fractalkine by laser treatment may contribute to improving the inflammatory response in the aging brain and in aging-related neurodegenerative diseases.

\subsection{Effects of PBM on signaling proteins in the aged brain}

PBM reduced the expression of ERK and p38 and increased the activation of ERK and STAT3 in the cortex of aged rats. In the hippocampus, PBM increased the expression of p70S6K and STAT5 and decreased the expression of p38. ERK activation is associated with proliferation, differentiation and cellular migration, having an effect opposite to $\mathrm{p38}$, which is activated by cellular stresses such as genotoxic, osmotic, hypoxic, or oxidative stress and it is connected to apoptosis and inflammatory responses (Kim and Choi, 2010; Zhang et al., 2016).

STAT3 modulates the expression of genes responsible for important physiological functions such as cell regulation and apoptosis control (Desrivières et al., 2006; Kim et al., 2010). STAT5 is linked to neuronal survival (Um and Lodish, 2006; Zhang et al., 2007). Also, STAT5 is necessary for the neuroprotective and neurotrophic effects of growth hormone on hippocampal neurons (Byts et al., 2008). However, STAT3 and STAT 5 brain levels are decreased during aging (Bazhanova and Anisimov, 2016). Nevertheless, laser treatment increased STAT3 activation and the expression of STAT5 in the cortex of aged rats. These 
observed changes in intracellular signaling proteins may be linked to the anti-inflammatory effects of PBM in the cortex and hippocampus of aged rats.

High levels of neuroinflammatory markers are observed during aging (Lee et al., 2000; Godbout et al., 2005), indicating a pro- and anti-inflammatory imbalance (Godbout and Johnson, 2009). In particular, it is possible that PBM of the neuroinflammatory response is related to increases in the activation of intracellular signaling proteins STAT3 and ERK in the cortical region. In this sense, STAT3 is a transcription factor that interacts with polypeptide receptors in the cell membrane, mediating extracellular signals such as growth factors and cytokines (Levy and Darnell, 2002). When activated by tyrosine phosphorylation, STAT3 dimerizes and translocate to the nucleus, thus activating the target genes (You, et al., 2015). The activation of STAT3 suppresses the expression of pro-inflammatory mediators, promoting an immune evasion and blocking the production and detection of inflammatory signals by several components of the immune system (Wang et al., 2004).

ERK can be activated by growth factors, such as the epidermal growth factor (EGF) that is associated with the attenuation of pro-inflammatory mediators (García-Ojalvo et al., 2019), activating Ras, which recruits Raf for the membrane. Raf activates Mek, which in turn activates ERK. ERK activation triggers cell proliferation, differentiation and cell migration (Kim and Choi, 2010). It is possible that the neuroinflammatory response in the cortex may trigger the activation of the ERK signaling pathways which in turn activates STAT3 (David et al., 1995). In this context, it is possible that the increased ERK activation is linked to the anti-inflammatory effect of laser treatment.

\subsection{Limitations}

We did not evaluate functional parameters, such as cognitive functions, since our goal was to investigate whether repeated laser treatment alters the cortical and hippocampal inflammatory and signaling profiles in aged rats. Also, the use of a small number of old rats with one laser dose is also a limitation. We used only one dose due to the difficulty in obtaining aged rats. This dose was used based on our previous studies showing anti-inflammatory effects in other tissues.

\subsection{Conclusion}

Taken together, our data suggest that transcranial PBM improves the inflammatory response and the activation of intracellular signaling proteins linked to vascular function and cell survival in the brain of aged rats.

\section{Declarations}

\section{Funding statement}

Coordenação de Aperfeiçoamento de Pessoal de Nível Superior (CAPES) and Fundação de Amparo à Pesquisa do Estado de São Paulo (FAPESP; \#2017/16443-0).

\section{Author contributions}


Conceived and designed the experiments: FSC, FCBM, and SGS. Performed the experiments: FSC and FCBM. Analyzed the data: FSC, and SGS.

Contributed reagents/materials/analysis tools: FSC, BHSA and SGS.

Wrote the manuscript: FSC, FGL and SGS. Approved the final version of the manuscript: FSC, FCBM, BHSA, FGL, and SGS.

\section{Availability of data and material}

Not applicable.

\section{Compliance with ethical standards}

All experimental protocols were approved by the ethics committee of the Universidade de Mogi das Cruzes (UMC) (\#003/2020).

\section{Consent to participate}

Not applicable.

\section{Consent for Publication}

Not applicable.

\section{Conflict of interest}

The authors declare that they have no conflicts of interest. All authors read and approved the final manuscript.

\section{Acknowledgements}

This study was supported by Coordenação de Aperfeiçoamento de Pessoal de Nível Superior (CAPES) and Fundação de Amparo à Pesquisa do Estado de São Paulo (FAPESP; \#2017/16443-0). F. GonzalezLima was supported by the Oskar Fischer Project Fund.

\section{References}

1. Almeida P, Lopes-Martins RÁB, Tomazoni SS, Albuquerque-Pontes GM, Santos LA, Vanin AA, Frigo L, Vieira RP, Albertini R, Carvalho PTC, Leal-Junior ECP (2013) Low-Level Laser Therapy and Sodium Diclofenac in Acute Inflammatory Response Induced by Skeletal Muscle Trauma: Effects in Muscle Morphology and $m$ RNA Gene Expression of Inflammatory Markers. Photochemistry photobiology 89(2):501-507

2. Anders JJ, Lanzafame RJ, Arany PR (2015) Low-level light/laser therapy versus photobiomodulation therapy. Photomed Laser Surg 33:183-184 
3. Arend WP, Palmer G, Gabay C (2008) IL-1, IL-18, and IL-33 families of cytokines. Immunological reviews 223(1):20-38

4. Barrett DW, Gonzalez-Lima F (2013) Transcranial infrared laser stimulation produces beneficial cognitive and emotional effects in humans. Neuroscience 230:13-23

5. Bazhanova ED, Anisimov VN (2016) The role of STAT transcription factors in apoptosis regulation of hypothalamic neurons in aging in HER-2/neu transgenic mice and wild-type FVB/N mice. In Doklady Biochemistry and Biophysics (Vol. 468, No. 1, pp. 217-219). Pleiades Publishing

6. Bellaver B, Souza DG, Souza DO, Quincozes-Santos A (2017) Hippocampal astrocyte cultures from adult and aged rats reproduce changes in glial functionality observed in the aging brain. Mol Neurobiol 54(4):2969-2985

7. Blanco NJ, Maddox WT, Gonzalez-Lima F (2017a) Improving executive function using transcranial infrared laser stimulation. Journal of neuropsychology 11(1):14-25

8. Blanco NJ, Saucedo CL, Gonzalez-Lima F (2017b) Transcranial infrared laser stimulation improves rule-based, but not information-integration, category learning in humans. Neurobiol Learn Mem 139:69-75

9. Bossù P, Ciaramella A, Salani F, Vanni D, Palladino I, Caltagirone C, Scapigliati G (2010) Interleukin18, from neuroinflammation to Alzheimer's disease. Curr Pharm Design 16(38):4213-4224

10. Byts N, Samoylenko A, Fasshauer T, Ivanisevic M, Hennighausen L, Ehrenreich H, Sirén AL (2008) Essential role for Stat5 in the neurotrophic but not in the neuroprotective effect of erythropoietin. Cell Death Differentiation 15(4):783-792

11. Cardoso FDS, Santos D, Gonzalez-Lima JCC, Araújo F, Lopes-Martins BHS, R. Á. B., Gomes da Silva, S (2021) Effects of Chronic Photobiomodulation with Transcranial Near-Infrared Laser on Brain Metabolomics of Young and Aged Rats. Molecular neurobiology, in press

12. Chung H, Dai T, Sharma SK, Huang YY, Carroll JD, Hamblin MR (2012) The nuts and bolts of low-level laser (light) therapy. Ann Biomed Eng 40(2):516-533

13. Council for International Organizations of Medical Sciences (1985) International guiding principles for biomedical research involving animals. Altern Lab Anim 12:ii

14. Cribbs DH, Berchtold NC, Perreau V, Coleman PD, Rogers J, Tenner AJ, Cotman CW (2012) Extensive innate immune gene activation accompanies brain aging, increasing vulnerability to cognitive decline and neurodegeneration: a microarray study. J Neuroinflamm 9(1):1-18

15. David M, Petricoin E, I. I. I., Benjamin C, Pine R, Weber MJ, Larner AC (1995) Requirement for MAP kinase (ERK2) activity in interferon alpha-and interferon beta-stimulated gene expression through STAT proteins. Science 269(5231):1721-1723

16. Desforges NM, Hebron ML, Algarzae NK, Lonskaya I, Moussa CEH (2012) Fractalkine mediates communication between pathogenic proteins and microglia: implications of anti-inflammatory treatments in different stages of neurodegenerative diseases. International Journal of Alzheimer's Disease, 2012 
17. Desrivières S, Kunz C, Barash I, Vafaizadeh V, Borghouts C, Groner B (2006) The biological functions of the versatile transcription factors STAT3 and STAT5 and new strategies for their targeted inhibition. J Mammary Gland Biol Neoplasia 11(1):75-87

18. Disner SG, Beevers CG, Gonzalez-Lima F (2016) Transcranial laser stimulation as neuroenhancement for attention bias modification in adults with elevated depression symptoms. Brain Stimul 9(5):780787

19. Eells JT, Gopalakrishnan S, Valter K (2016) Near-infrared photobiomodulation in retinal injury and disease. In: Retinal Degenerative Diseases. Springer, Cham, pp 437-441

20. El Massri N, Lemgruber AP, Rowe IJ, Moro C, Torres N, Reinhart F, Chabrol C, Benabid AL, Mitrofanis J (2017) Photobiomodulation-induced changes in a monkey model of Parkinson's disease: changes in tyrosine hydroxylase cells and GDNF expression in the striatum. Exp Brain Res 235(6):1861-1874

21. García-Ojalvo A, Berlanga Acosta J, Figueroa-Martínez A, Béquet-Romero M, Mendoza-Marí Y, Fernández-Mayola M, Fabelo-Martínez A, Guillén-Nieto G (2019) Systemic translation of locally infiltrated epidermal growth factor in diabetic lower extremity wounds. Int Wound J 16(6):1294-1303

22. Hanzel CE, Pichet-Binette A, Pimentel LS, lulita MF, Allard S, Ducatenzeiler A, Carmo S, Cuello AC (2014) Neuronal driven pre-plaque inflammation in a transgenic rat model of Alzheimer's disease. Neurobiol Aging 35(10):2249-2262

23. Haslerud S, Lopes-Martins RAB, Frigo L, Bjordal JM, Marcos RL, Naterstad IF, Magnussen RH, Joensen $J(2017)$ Low-level laser therapy and cryotherapy as mono-and adjunctive therapies for Achilles tendinopathy in rats. Photomed Laser Surg 35(1):32-42

24. Holmes E, Barrett DW, Saucedo CL, O'Connor P, Liu H, Gonzalez-Lima F (2019) Cognitive enhancement by transcranial photobiomodulation is associated with cerebrovascular oxygenation of the prefrontal cortex. Front NeuroSci 13:1129

25. Hong S, Beja-Glasser VF, Nfonoyim BM, Frouin A, Li S, Ramakrishnan S, Merry KM, Shi Q, Rosenthal A, Barres BA, Lemere CA, Selkoe DJ, Stevens B (2016) Complement and microglia mediate early synapse loss in Alzheimer mouse models. Science 352(6286):712-716

26. Hwang J, Castelli DM, Gonzalez-Lima F (2016) Cognitive enhancement by transcranial laser stimulation and acute aerobic exercise. Lasers in medical science 31(6):1151-1160

27. Godbout JP, Chen J, Abraham J, Richwine AF, Berg BM, Kelley KW, Johnson RW (2005) Exaggerated neuroinflammation and sickness behavior in aged mice following activation of the peripheral innate immune system. The FASEB journal 19(10):1329-1331

28. Godbout JP, Johnson RW (2009) Age and neuroinflammation: a lifetime of psychoneuroimmune consequences. Immunol Allergy Clin North Am 29(2):321-337

29. Kim DJ, Tremblay ML, DiGiovanni J (2010) Protein tyrosine phosphatases, TC-PTP, SHP1, and SHP2, cooperate in rapid dephosphorylation of Stat3 in keratinocytes following UVB irradiation. PloS one 5(4):e10290

30. Kim EK, Choi EJ (2010) Pathological roles of MAPK signaling pathways in human diseases. Biochimica et Biophysica Acta (BBA)-Molecular Basis of Disease 1802(4):396-405 
31. Lee CK, Weindruch R, Prolla TA (2000) Gene-expression profile of the ageing brain in mice. Nat Genet 25(3):294-297

32. Levy DE, Darnell JE (2002) Stats: transcriptional control and biological impact. Nature reviews Molecular cell biology 3(9):651-662

33. Liu YP, Lin HI, Tzeng SF (2005) Tumor necrosis factor-a and interleukin-18 modulate neuronal cell fate in embryonic neural progenitor culture. Brain research 1054(2):152-158

34. Liva SM, de Vellis J (2001) IL-5 induces proliferation and activation of microglia via an unknown receptor. Neurochem Res 26(6):629-637

35. Lu Y, Wang R, Dong Y, Tucker D, Zhao N, Ahmed ME, Zhu L, Liu TCY, Cohen RM, Zhang Q (2017) Lowlevel laser therapy for beta amyloid toxicity in rat hippocampus. Neurobiol Aging 49:165-182

36. Naterstad IF, Rossi RP, Marcos RL, Parizzoto NA, Frigo L, Joensen J, Lopes-Martins PSL, Bjordal JM, Lopes-Martins RAB (2018) Comparison of photobiomodulation and anti-inflammatory drugs on tissue repair on collagenase-induced achilles tendon inflammation in rats. Photomed Laser Surg 36(3):137-145

37. Norden DM, Godbout JP (2013) Microglia of the aged brain: primed to be activated and resistant to regulation. Neuropathology applied neurobiology 39(1):19-34

38. Muili KA, Gopalakrishnan S, Eells JT, Lyons JA (2013) Photobiomodulation induced by $670 \mathrm{~nm}$ light ameliorates MOG35-55 induced EAE in female C57BL/6 mice: a role for remediation of nitrosative stress. PloS one 8(6):e67358

39. Muili KA, Gopalakrishnan S, Meyer SL, Eells JT, Lyons JA (2012) Amelioration of experimental autoimmune encephalomyelitis in C57BL/ 6 mice by photobiomodulation induced by $670 \mathrm{~nm}$ light. PloS one 7(1):e30655

40. O’Donnell CM, Barrett DW, Fink LH, Garcia-Pittman EC, G-Lima, F (2021) Transcranial infrared laser stimulation improves cognition in older bipolar patients: proof of concept study. Journal of Geriatric Psychiatry and Neurology, in press

41. O'Donnell E, Vereker E, Lynch MA (2000) Age-related impairment in LTP is accompanied by enhanced activity of stress-activated protein kinases: analysis of underlying mechanisms. Eur J Neurosci 12(1):345-352

42. Rojas JC, Gonzalez-Lima F (2011) Low-level light therapy of the eye and brain. Eye brain 3:49

43. Rojas JC, Lee J, John JM, Gonzalez-Lima F (2008) Neuroprotective effects of near-infrared light in an in vivo model of mitochondrial optic neuropathy. J Neurosci 28(50):13511-13521

44. Saini MG, Bix GJ (2012) Oxygen-glucose deprivation (OGD) and interleukin-1 (IL-1) differentially modulate cathepsin B/L mediated generation of neuroprotective perlecan LG3 by neurons. Brain research 1438:65-74

45. Salehpour F, Ahmadian N, Rasta SH, Farhoudi M, Karimi P, Sadigh-Eteghad S (2017) Transcranial low-level laser therapy improves brain mitochondrial function and cognitive impairment in Dgalactose-induced aging mice. Neurobiol Aging 58:140-150 
46. Salehpour F, De Taboada L, Cassano P, Kamari F, Mahmoudi J, Ahmadi-Kandjani S, Rasta SH, Sadigh-Eteghad S (2018) A protocol for transcranial photobiomodulation therapy in mice. JoVE (Journal of Visualized Experiments), (141), e59076

47. Salgado AS, Zângaro RA, Parreira RB, Kerppers II (2015) The effects of transcranial LED therapy (TCLT) on cerebral blood flow in the elderly women. Lasers in medical science 30(1):339-346

48. Salmeron K, Aihara T, Redondo-Castro E, Pinteaux E, Bix G (2016) IL-1alpha induces angiogenesis in brain endothelial cells in vitro: implications for brain angiogenesis after acute injury. Journal of neurochemistry 136(3):573-580

49. Saltmarche AE, Naeser MA, Ho KF, Hamblin MR, Lim L (2017) Significant improvement in cognition in mild to moderately severe dementia cases treated with transcranial plus intranasal photobiomodulation: case series report. Photomed Laser Surg 35(8):432-441

50. Saucedo CL, Courtois EC, Wade ZS, Kelley MN, Kheradbin N, Barrett DW, Gonzalez-Lima F (2021) Transcranial laser stimulation: mitochondrial and cerebrovascular effects in younger and older healthy adults. Brain Stimulation, in press

51. Schiffer F, Johnston AL, Ravichandran C, Polcari A, Teicher MH, Webb RH, Hamblin MR (2009) Psychological benefits 2 and 4 weeks after a single treatment with near infrared light to the forehead: a pilot study of 10 patients with major depression and anxiety. Behav Brain Funct 5(1):1-13

52. Stephan AH, Madison DV, Mateos JM, Fraser DA, Lovelett EA, Coutellier L, Kim L, Tsai HH, Huang EJ, Rowitch DH, Berns DS, Tenner AJ, Shamloo M, Barres BA (2013) A dramatic increase of C1q protein in the CNS during normal aging. J Neurosci 33(33):13460-13474

53. Tian F, Hase SN, Gonzalez-Lima F, Liu H (2016) Transcranial laser stimulation improves human cerebral oxygenation. Lasers Surg Med 48(4):343-349

54. Tomazoni SS, Leal-Junior ECP, Pallotta RC, Teixeira S, de Almeida P, Lopes-Martins R Á. B (2017) Effects of photobiomodulation therapy, pharmacological therapy, and physical exercise as single and/or combined treatment on the inflammatory response induced by experimental osteoarthritis. Lasers in medical science, 32(1), 101-108

55. Um M, Lodish HF (2006) Antiapoptotic effects of erythropoietin in differentiated neuroblastoma SHSY5Y cells require activation of both the STAT5 and AKT signaling pathways. J Biol Chem 281(9):5648-5656

56. Vargas E, Barrett DW, Saucedo CL, Huang LD, Abraham JA, Tanaka H, Haley AP, Gonzalez-Lima F (2017) Beneficial neurocognitive effects of transcranial laser in older adults. Lasers in medical science 32(5):1153-1162

57. Wang T, Niu G, Kortylewski M, Burdelya L, Shain K, Zhang S, Bhattacharya R, Gabrilovich D, Heller R, Coppola D, Dalton W, Jove R, Pardoll D, Yu H (2004) Regulation of the innate and adaptive immune responses by Stat-3 signaling in tumor cells. Nature medicine 10(1):48-54

58. Wang X, Tian F, Reddy DD, Nalawade SS, Barrett DW, Gonzalez-Lima F, Liu H (2017) Up-regulation of cerebral cytochrome-c-oxidase and hemodynamics by transcranial infrared laser stimulation: a 
broadband near-infrared spectroscopy study. Journal of Cerebral Blood Flow Metabolism 37(12):3789-3802

59. You L, Wang Z, Li H, Shou J, Jing Z, Xie J, Sui X, Pan H, Han W (2015) The role of STAT3 in autophagy. Autophagy 11(5):729-739

60. Zhang F, Wang S, Cao G, Gao Y, Chen J (2007) Signal transducers and activators of transcription 5 contributes to erythropoietin-mediated neuroprotection against hippocampal neuronal death after transient global cerebral ischemia. Neurobiol Dis 25(1):45-53

61. Zhang J, Wang X, Vikash V, Ye Q, Wu D, Liu Y, Dong W (2016) ROS and ROS-mediated cellular signaling. Oxidative medicine and cellular longevity, 2016

62. Zhu C, Huang Z, Gao J, Zhang Y, Wang X, Karlsson N, Li Q, Lannering B, Bjork-Erikson T, Kuhn HG, Blomgren K (2009) Irradiation to the immature brain attenuates neurogenesis and exacerbates subsequent hypoxic-ischemic brain injury in the adult. Journal of neurochemistry 111(6):1447-1456

\section{Figures}
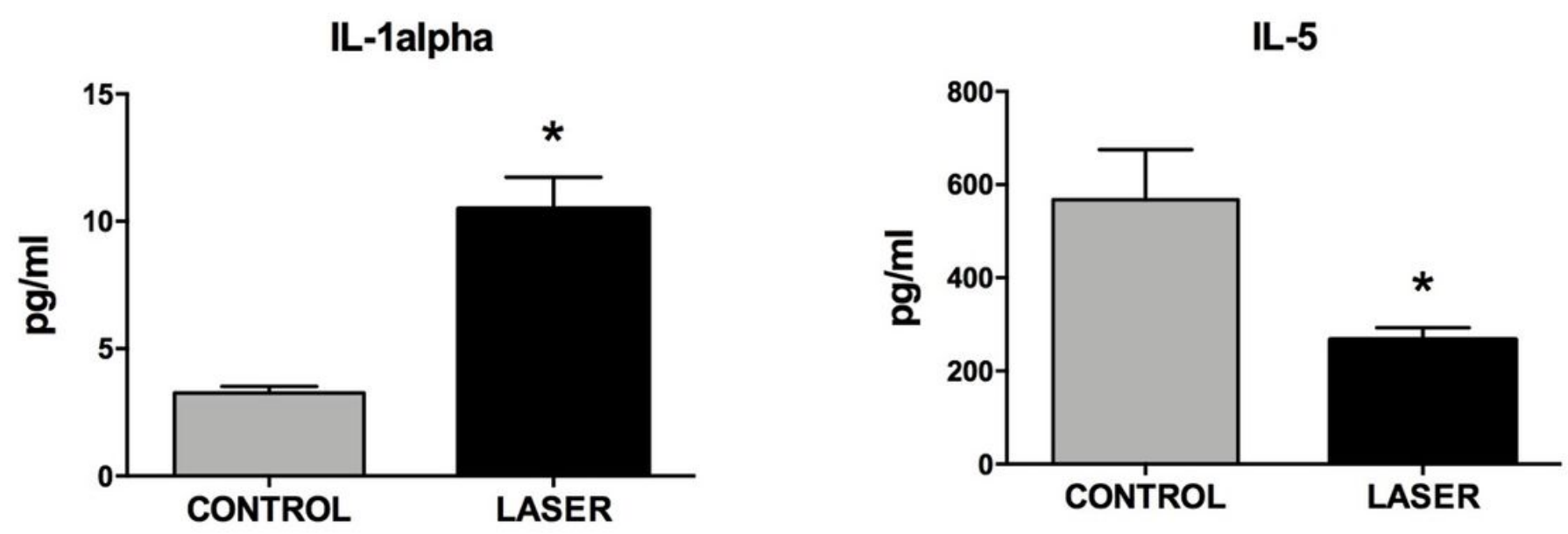

Figure 1

Cortical levels of IL- 1 alpha and IL-5 in rats from control $(n=5)$ and laser $(n=5)$ groups. The laser treatment increased IL-1alpha level and reduced IL-5 level in aged rats $\left(^{*}\right)$. Data are showed in picogram per microgram of protein $(p<0.05$; Mann-Whitney test). 


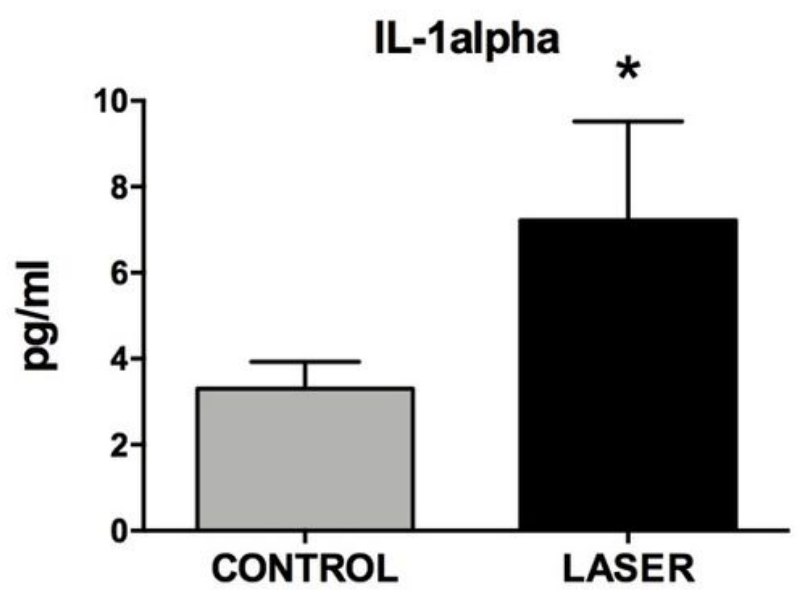

IL-18

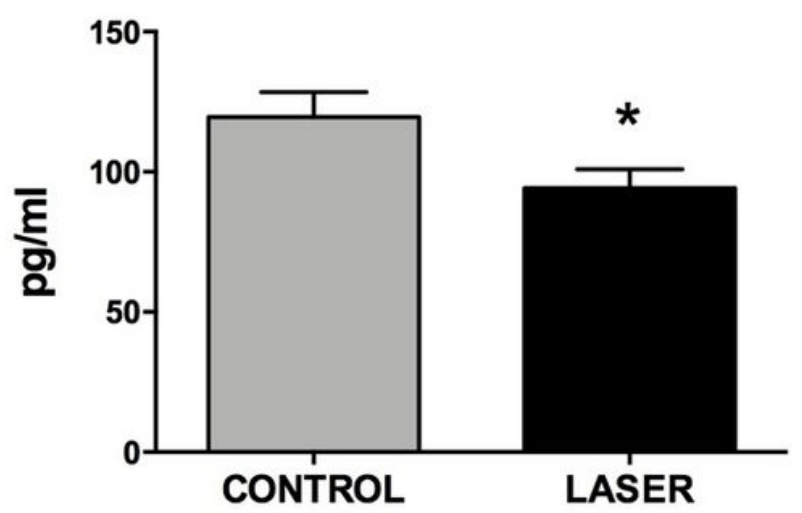

IL-5

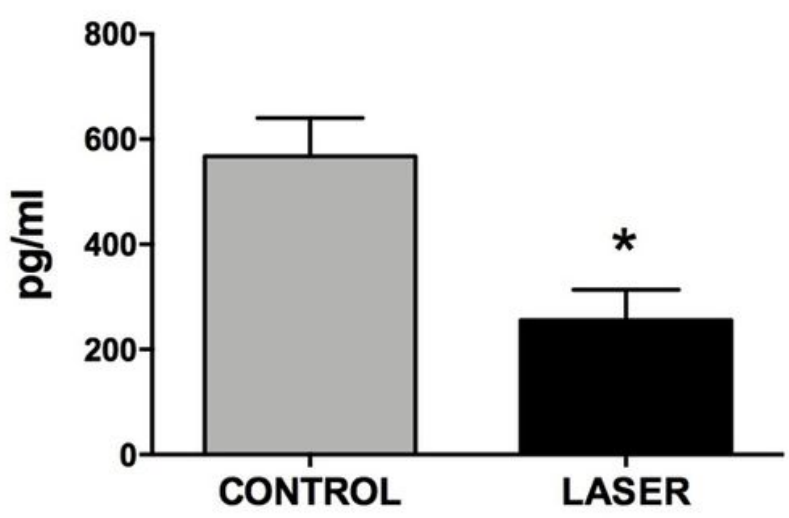

Fractalkine

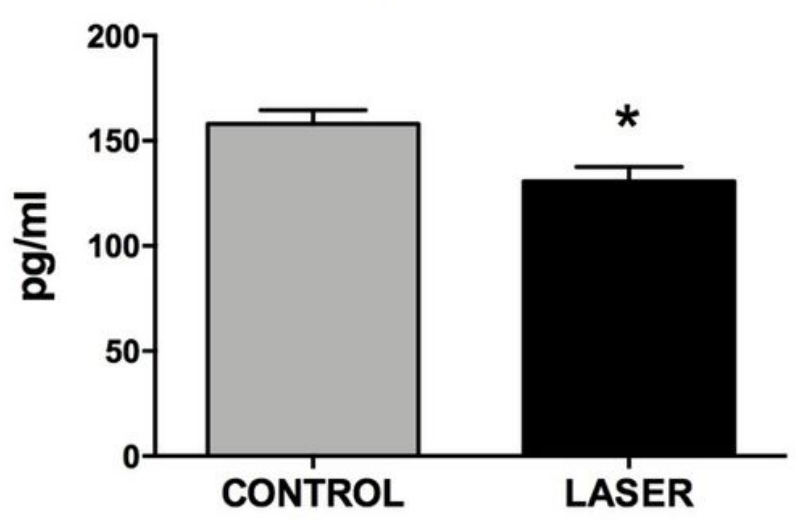

Figure 2

Hippocampal levels of IL-1alpha, IL-5, IL-18 and Fractalkine in rats from control $(n=5)$ and laser $(n=4)$ groups. The laser treatment increased IL-1alpha level and reduced IL-5, IL-18 and fractalkine levels in aged rats $\left.{ }^{*}\right)$. Data are showed in picogram per microgram of protein $(p<0.05 ;$ Mann-Whitney test). 
ERK

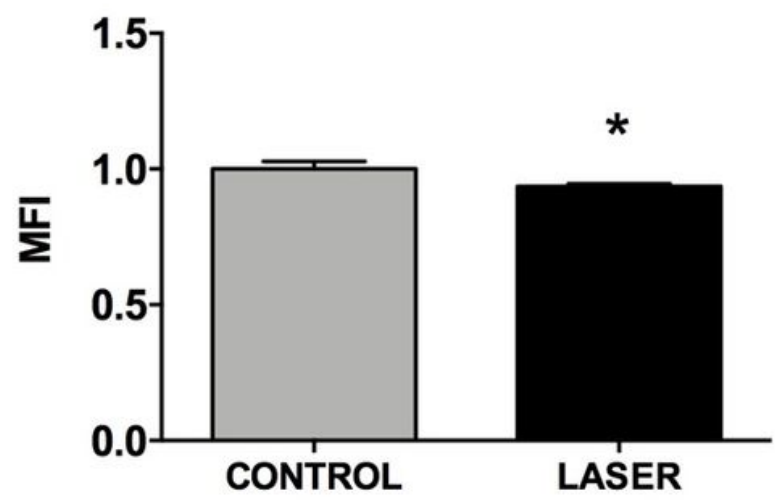

p-STAT3/ STAT3

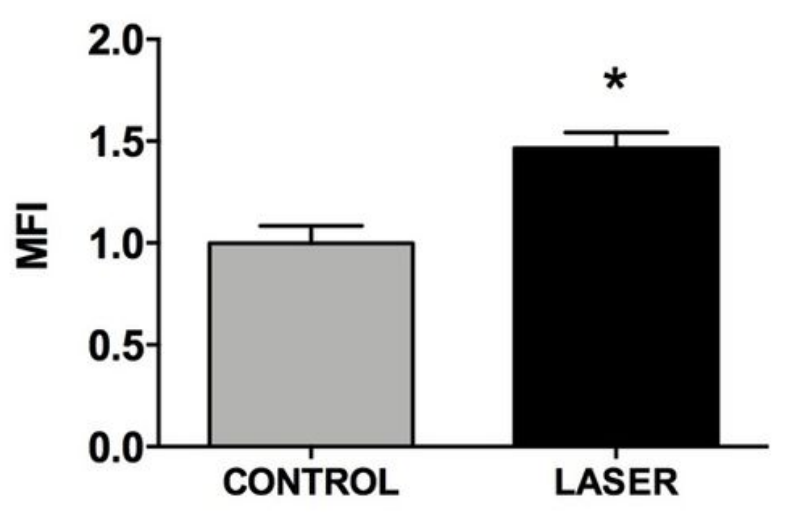

p38

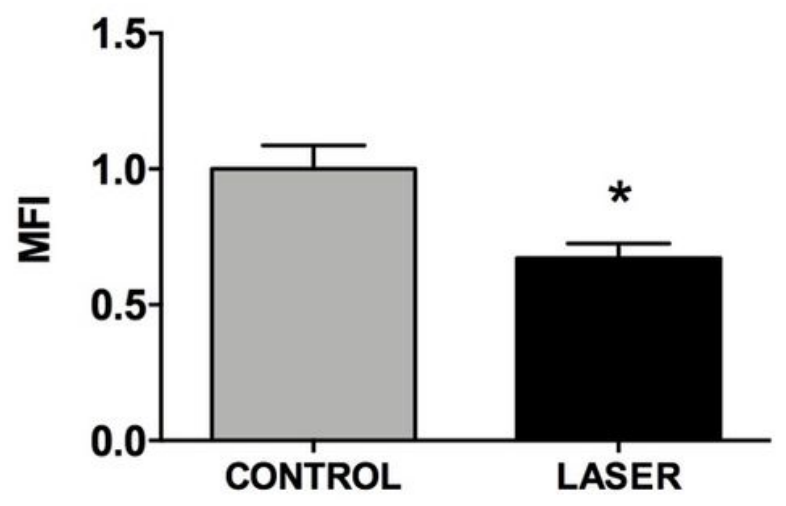

p-ERK/ERK

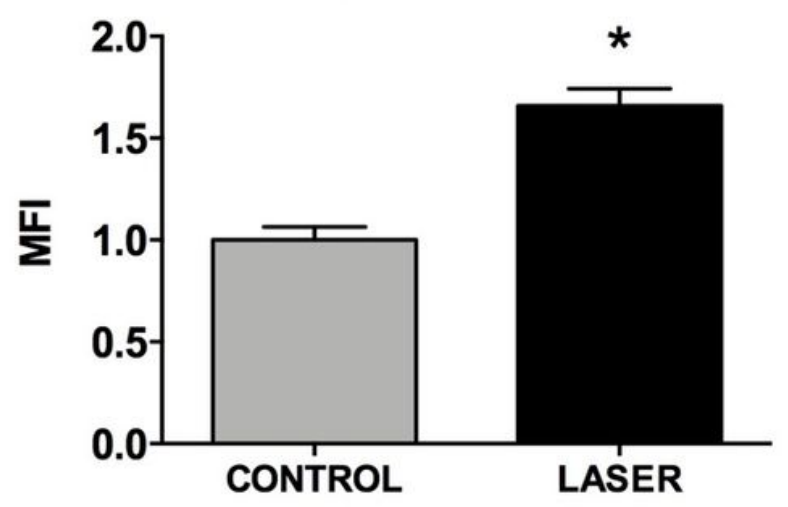

Figure 3

Cortical expression of ERK and p38 and activation of STAT3 and ERK in rats from control $(n=5)$ and laser $(n=5)$ groups. The laser treatment reduced the expression of ERK and p38 and increased the activation of STAT3 and ERK in aged rats $\left(^{*}\right)$. Data were normalized to the mean fluorescence intensity (MFI) of the control group ( $p<0.05$; Mann-Whitney test).

p70S6K

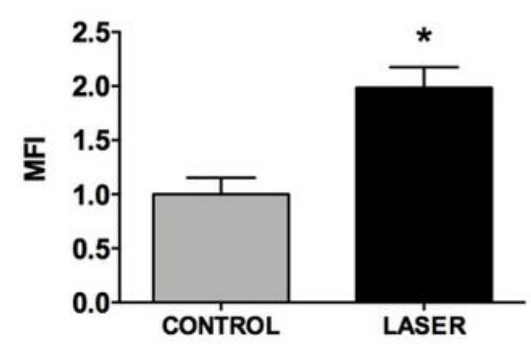

STAT5

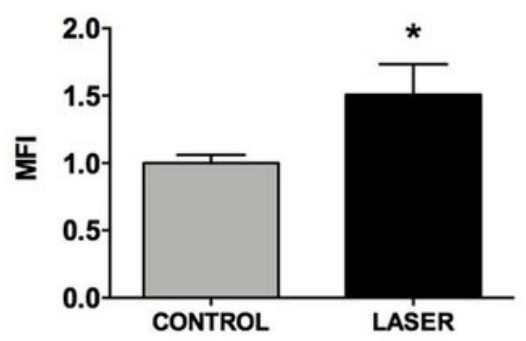

p38

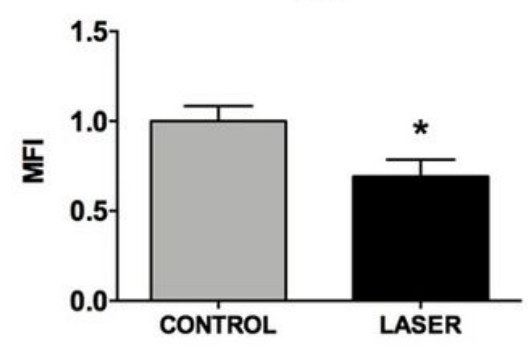

Figure 4

Hippocampal expression of p70S6K, STAT5 and p38 in rats from control $(n=5)$ and laser $(n=5)$ groups. The laser treatment increased the expression of p70S6K and STAT5 and reduced the expression of p38 in 
aged rats $\left(^{*}\right)$. Data were normalized to the mean fluorescence intensity $(\mathrm{MFI})$ of the control group $(\mathrm{p}<0.05$; Mann-Whitney test).

\section{Supplementary Files}

This is a list of supplementary files associated with this preprint. Click to download.

- Supplementarymaterial.docx 